\title{
Sagging-collapse sinkholes: simulation modelling
}

\author{
Victor Khomenko, ${ }^{1, *}$ \\ ${ }^{1}$ Moscow State University of Civil Engineering, 26, Yaroslavskoye Shosse, 129337, Moscow, Russia
}

\begin{abstract}
In the paper a kind of sinkholes is considered, which is typical for areas where soluble rocks are covered by clay's layer overlapped by saturated sands. The presence in soluble rocks of non-filled cavity contacting with covering clays is necessary to the sinkhole formation, however it can be provoked not only by cavity's enlarging but else by changes of groundwater levels. The mechanism of this complex process has been researched by its in-laboratory simulation modelling, and its results can possibility to the author to name this phenomenon as "saggingcollapse sinkholes", because it includes sagging and collapse of clays accompanied by downward moving of sands and sometimes by their liquefaction. Modelling technology is given in the paper in detail and the conception of investigated process is offered. Except experimental study of sagging-sinkhole formation the purposes of the work was quantitative forecasting of this geological phenomenon. Forecasts have been developed that allow calculating the diameter of the expected sinkhole, particularly. An assessment of their reliability is given.
\end{abstract}

\section{Introduction}

One understands the term "sinkhole" variously but chiefly as karst manifestation [1]. In this paper sinkholes consider exclusively as karst phenomena, according Back's view [2]. Sinkholes, which form in the areas where soluble rocks are covered by soils, Waltham and Fookes [3] name as "dropout sinkholes" and Gutiérrez et al. [4] as "cover collapse sinkholes". In the United States Zisman [5] considers that these sinkholes can be caused by soil collapse without or with soil piping. Nowadays in Russia Khomenko and Tolmachev [6] distinguish four genetic types of sinkholes formed in soil cover above karst cavities: collapse sinkholes, sagging-collapse sinkholes, liquefaction-collapse sinkholes, and pipingcollapse sinkholes. For a number of reasons, in recent years, the attention of experts working in the field of engineering karstology has been mainly attracted by liquefactioncollapse and piping-collapse sinkholes. Not the last role in this was played by the idea that the mechanism of collapse- and sagging-collapse sinkhole formation is simple and understandable, since such sinkholes are formed solely under the influence of gravitational forces. In fact, this is not true.

The fact is that for the formation of a collapse- or sagging-collapse sinkhole, it is necessary that the cavity be covered by a layer of sufficiently firm and almost impermeable

*Corresponding author: khomenko_geol@mail.ru 
clayey soils. Where the roof of this layer reaches the earth's surface, the sinkhole formation actually proceeds according to a rather simple scheme, even if the cavity is filled with water under pressure and hydrostatic forces are superimposed on gravitational forces. According Khomenko and Tolmachev [6], this is the process of a collapse sinkhole formation, but if saturated cohesionless soils lie above a layer of clayey soils, sagging-collapse sinkholes formation takes place and the mechanism of this process is significantly complicated. However, it is necessary to comprehend mechanisms of all types of sinkhole formations in detail in order to solve not only theoretical but practical tasks. For example, such knowledge gives the possibility to choose correctly mitigation measures [7] and to make a forensic assessment of all causation under an accident due to a sinkhole appearance [8].

To predict the conditions and parameters of the collapse sinkhole formation, relatively simple geomechanical models based on well-known theoretical solutions can be used [9]. Such models are of little use for the sagging-collapse sinkholes, and the development of new ones seems extremely difficult, because in this case, the downward movement of rocks does not come down to purely gravitational collapse, which can be simply interpreted mathematically. In this regard, for the prognostic assessment of the danger of saggingcollapse sinkhole formation, it seems advisable to use simulation modelling. Such modelling was carried out in relation to the settings of the city of Dzerzhinsk, Nizhny Novgorod Region, for which the formation of sinkholes of the genetic type under consideration is typical.

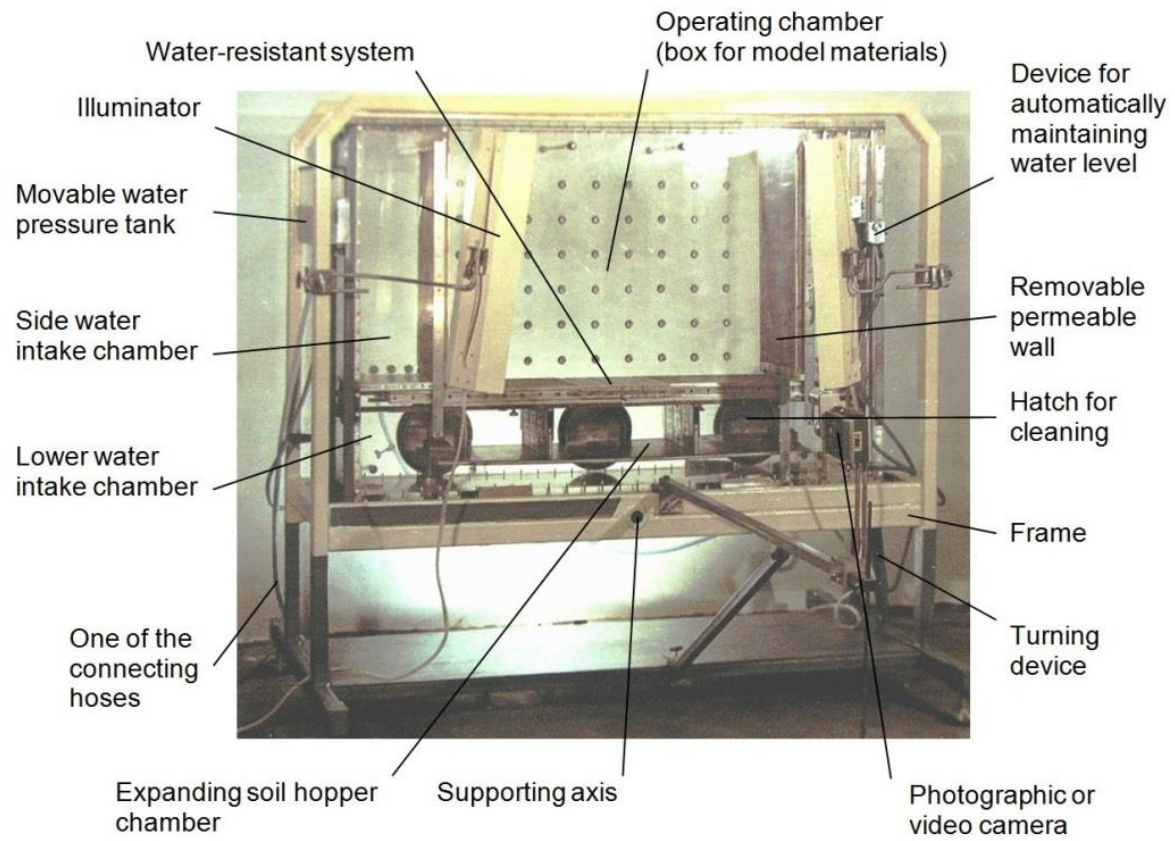

Fig. 1. Modelling apparatus designed by Khomenko, Makhan'ko, Isaev et al. [10] to simulate soil failures, caused by groundwater flow and hidden from direct observation.

\section{Materials and methods}

The experiments were carried out by means of special equipment (Fig. 1), protected by the patent of the Russian Federation [10], which is a tank mounted on a horizontal supporting axis inside a rigid fixed frame. To simulate the sinkhole formation, the use of all the design elements of the apparatus was not required. In this case (Fig. 2), with the horizontal 
position of the tank, its lower chamber imitated flooded soluble rocks, and the soil hopper chamber and the hole located above it in the water-resistant system - a karst cavity. The model materials filling the working chamber reproduced the two-layer stratum of insoluble covering soils: clays covered by saturated sands. It was necessary to study the reaction of the model to the appearance and growth of the cavity under the clay layer.

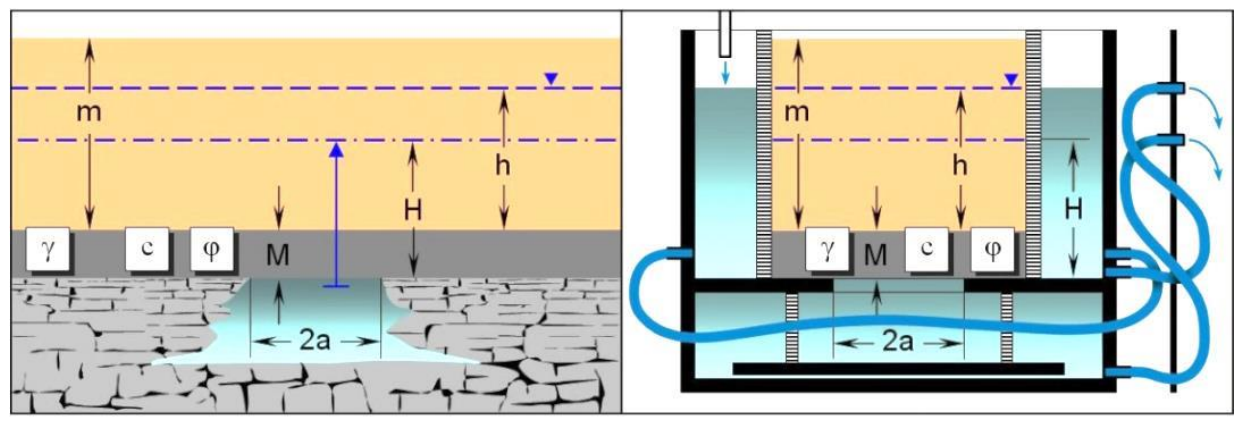

Fig. 2. Schematized natural settings for the formation of sagging-collapse sinkholes (left) and the technological scheme of their in-laboratory simulation modelling (right). See the text for explanations.

An individual experiment was prepared as follows. The water-resistant system was mounted so that it was possible to create a single slit-like through hole in it, which was capable of expanding discretely in two opposite directions. A layer of clay imitating material and having certain physical and mechanical properties was laid on the waterresistant system. A layer of sand imitating material of the desired height was laid on it.

In the preparation of 10 experiments from the designed 11, all three hydraulically interconnected water intake chambers were gradually filled with water to the intended level through one of the side chambers. In experiments No.1 and No.8, the preparation of the experiment ended on this. In some experiments, the lower position of the piezometric surface of karst waters with respect to the free surface of supra-karst waters was reproduced. To do this, the hoses connecting the side water intake chambers to the lower one were closed, and the water pressure in it gradually decreased to a predetermined value. To simulate the opposite situation in experiment No.10, water was supplied to the apparatus only through a movable pressure tank connected by a hose to the lower water intake chamber. At the same time, there was no hydraulic connection between the side chambers and the bottom chamber, and a certain piezometric pressure was created in it by lifting the pressure tank above the bottom of the box filled by model materials.

The experiment began with the creation of a through transverse gap in the center of the water-resistant system with a width of about $10 \mathrm{~mm}$. In the course of the experiment, the gap expanded discretely, alternately to the right or to the left with an increment of its width by one step by approximately the same amount. The transition to a new stage of expansion of the gap was carried out after the complete cessation of changes in the stress state of the model, which were recorded using the RVINDS-P-03 radio wave indicator mounted on its surface, developed by A.P. Bars. As a rule, the duration of one step did not exceed 5 minutes.

The discrete expansion of a rectangular opening in the water-resistant system, which can no longer be called a gap with a width of more than $10 \mathrm{~cm}$, continued until there was a through collapse of the clay imitating material above it and a downward movement of the sand imitating material. After that, the water supply to the apparatus was stopped and, thereby, the automatic maintenance of the planned water levels and pressures in the water intake chambers was stopped. It was the end of the experiment. 
The processes and phenomena observed during the experiments were documented using sketches, photo and video filming, as well as using verbal description in a special journal. Unfortunately, in some cases, the downward movement of sand imitating material did not appear on the surface of the model within clear boundaries. However, this did not prevent the full-fledged statistical processing of experimental data.

In each experiment, only one parameter was subjected to a discrete change in increments of about $1 \mathrm{~cm}$ from zero to a certain critical value $\left(2 a_{0}\right)$ - the width of the through hole in the water-resistant system $(2 a)$. The structure of the model and the properties of its materials, as well as the levels and pressures of water in the intake chambers, were remaining unchanged, as shown in right part of Figure 2.

In addition to studying the mechanism of formation of karst sinkholes of a given genetic type, the experiments aimed to establish the dependence of parameter $2 a_{0}$ on the height of the layer of clay imitating material $(M)$, its unit weight $(\gamma)$, cohesion $(c)$, and friction angle $(\varphi)$, on the height of the layer of sand imitating material $(m)$, on the height of the water column in the side chambers, counting from the roof of the layer of clay imitating material $(h)$, and on the pressure of water on the floor of this layer, expressed in the height of the corresponding water column $(H)$. This was achieved by conducting a series of experiments designed so that the values of the above parameters, which play the role of arguments in the desired dependence, in a certain way changed from experiment to experiment.

A very important element in the experimental design was the selection of the properties of the model materials, and the requirements for materials imitating sands and clays were different. In the first case, some kind of granular incoherent material was needed, the same for the entire series of experiments, having almost zero cohesion and the same friction angle as the covering sands. In the second case, a cohesive plastic material should be used, the properties of which can be controlled over a fairly wide range.

In accordance with these requirements, fine gravel with a negative linearity parameter and an angle of internal friction ranging from $31^{\circ}-42^{\circ}$ was chosen as a sand imitating material. This material is completely equivalent to a simulated medium, since according to the results of site investigations performed in Dzerzhinsk, the averaged values of the friction angle here are $33^{\circ}$ for fine sands, $37^{\circ}$ for medium-sized sands, and $39^{\circ}$ for coarse sands.

Clays were reproduced on models using well-proven mixtures of liquid transformer oil with solid granular substances: fine quartz sand (fraction of $0.10-0.25 \mathrm{~mm}$ ), dry powdery bentonite clay and ground muscovite, about $0.3 \mathrm{~mm}$ in size. These materials are well "managed", do not change their properties for many hours and, which is especially important for solving the task, are almost water resistant. During experiments, exfoliation processes were observed in clay imitating materials, which indicates their good correspondence to the original.

The relative critical width of the karst cavity $\left(R=2 a_{0} / b\right.$, where $b$ is an indicator having a dimension of length) was taken as the dependent variable, and the independent variables were water cut of the sands $\left(Z_{1}=h / m\right)$, relative thickness of the clays $\left(Z_{2}=M / m\right)$, relative pressure of karst waters $\left(Z_{3}=H / M\right)$, modified Newton number $\left(Z_{4}=c / \gamma M\right)$ and the friction coefficient of clays $\left(Z_{5}=\operatorname{tg} \varphi\right)$. The choice of independent variables was not random. The first and third variables characterize the hydrogeological situation and the stress state of the soil cover, the second - its structure, and the fourth and fifth - the strength of the clays. Thus, the main factors that determine the critical size of the karst cavity covered by the clays, which ensures their collapse, were taken into account.

The process reproduced using the model cannot be attributed to well-studied ones. Therefore, the so-called orthogonal factorial design of experiments [11] was adopted, which is optimal for this situation (Fig. 3). For the period of the modelling, there were some deviations from the original design due to technological reasons. 


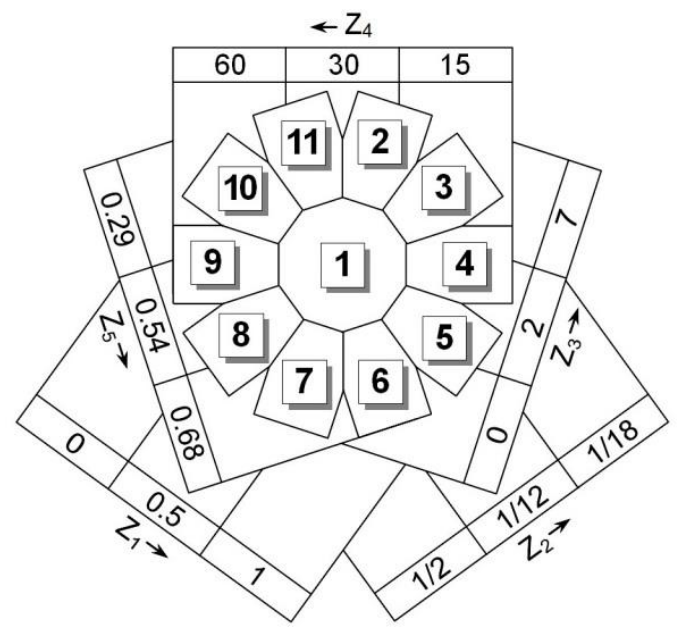

Fig. 3. The design of experiments ( 5 independent variables, 3 levels of each variable, 11 test conditions).

\section{Results}

During the experiments, a certain sequence of processes and phenomena leading to the formation of a final depression on the surface of the model was observed (Table 1). A complete set of these phenomena was not observed in any experiment. However, against the general background, experiment No.1 can be considered the most representative one (Fig. 4). The generalized picture is as follows.

Table 1. The processes, which were observed during the modelling.

\begin{tabular}{|c|c|c|c|c|c|c|c|c|c|c|c|c|c|}
\hline \multirow{2}{*}{\multicolumn{3}{|c|}{ Failures }} & \multicolumn{11}{|c|}{ Experiment numbers } \\
\hline & & & 1 & 2 & 3 & 4 & 5 & 6 & 7 & 8 & 9 & 10 & 11 \\
\hline \multirow{4}{*}{ 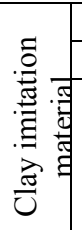 } & & + & + & + & + & + & + & - & + & + & + & - \\
\hline & \multicolumn{2}{|c|}{ Visible sagging } & + & + & - & + & + & + & + & + & + & + & + \\
\hline & \multirow[b]{2}{*}{$\frac{0}{\tilde{n}}$} & internal & - & - & - & + & + & - & - & + & - & - & - \\
\hline & & through & + & + & + & + & + & + & + & + & + & + & + \\
\hline \multirow{4}{*}{ 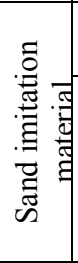 } & \multicolumn{2}{|c|}{$\begin{array}{l}\text { Erosion by the upward water } \\
\text { flow }\end{array}$} & + & - & - & - & - & - & - & - & - & - & - \\
\hline & \multirow{3}{*}{ 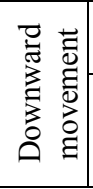 } & $\begin{array}{l}\text { smooth, with a } \\
\text { subsidence formation }\end{array}$ & + & - & - & - & - & - & - & - & + & - & - \\
\hline & & e internal & - & - & + & - & - & - & - & - & - & - & + \\
\hline & & $\begin{array}{ll}\text { जี } & \text { through, with a sink } \\
\text { formation }\end{array}$ & + & + & + & + & + & + & + & + & + & + & + \\
\hline
\end{tabular}

Note: the "+" sign indicates the presence of a process, and the "-" sign indicates the absence of its visual manifestations.

When a widening slit-like hole in a water-resistant system reaches a certain width, the process of exfoliation of clay imitating material was observed in almost all experiments. The laws of this process are currently well studied [12]. In this case, at first it was possible to see the sedimentation of flakes on the bottom of the soil hopper chamber, which were separated from the material and measured by the first millimeters. Their amount and size clearly increased with the growth of the gap. Then, in all experiments where it proceeded 
(except for No.3), the process of exfoliation of the clay imitating material passed to the stage of the formation of horizontal and, after them, vertical cracks, the number and sizes of which also increased with increasing of gap in the water-resistant system. Cracks closed in curved arches, and in three experiments, there was an internal collapse of the material in the contours of these arches, without reaching the layer surface.

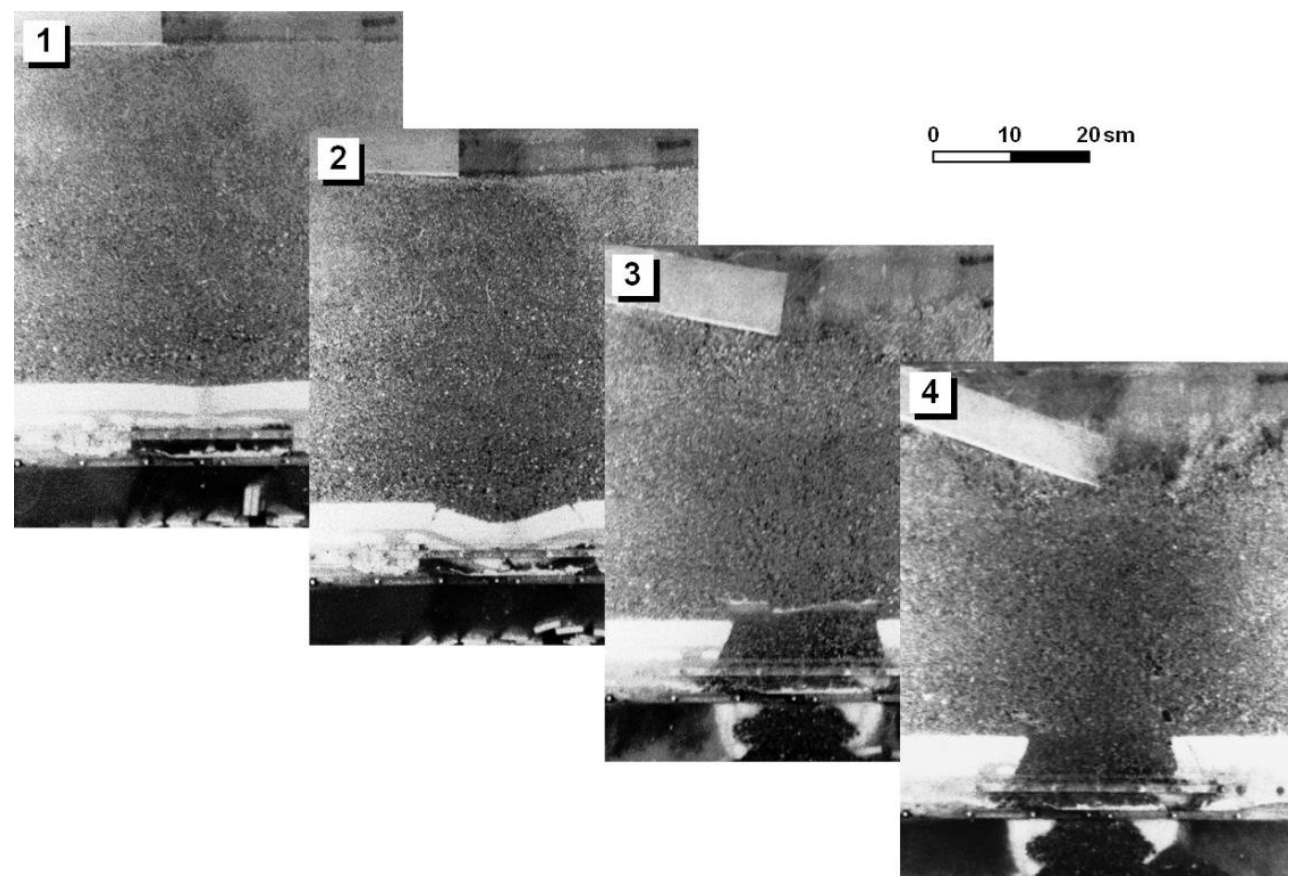

Fig. 4. The result of simulation modelling of sagging-collapse sinkhole formation during experiment No.1.

Where: 1, Visible sagging of clay imitation material and its exfoliation. 2, Through destruction of clay imitation material, the beginning of smooth downward movement of sand imitation material, and the formation of subsidence on the model surface. 3, Formation of a cavity filled with water in model materials, completion of the subsidence formation, and the beginning of the formation of a depression on the surface of the model. 4, Disappearance of the cavity filled with water and the completion of the final depression formation.

Where it took place, the exfoliation of the clay imitating material developed against the background of the progressive sagging of a layer of this material over a growing hole in the water-resistant system. In experiment No.3, the width of the hole was so small that no sagging was visually observed until the end of the experiment. However, this process undoubtedly proceeded in the remaining experiments and everywhere was accompanied by a smooth downward movement of material imitating sands, but visible subsidence on the surface of the model was recorded only in two cases. In all experiments, the sagging of the layer consisting of a clay imitating material ended in its through collapse.

Following this, almost instantly there was a sharp downward movement of the sand imitating material. In the majority of cases, it was straight through at once, i.e. it came to the surface of the model in the form of a sink and was limited to a well-visible surface resembling a vertical parabola with its vertex pointing downward without a lower segment. The delay in this process noted in two experiments manifested itself in the form of the 
initial fall of the model material bounded by the curved arch. However, the intermediate cavities formed in this case instantly collapsed, and the process came to the surface.

In the course of a unique experiment No.1 (Fig. 4), it was possible to see how has formed the rupture in the sand imitating material during its fall into the soil hopper chamber. Immediately, water squeezed out of the lower chamber when the clay imitating material falls into the soil hopper chamber rushed into the rupture. Formed as a result of erosion by an ascending water stream, the cavity filled with water had a vertical section in the form of a trapezoid facing downward and "leaning" on a through breach in a clay imitating material. This cavity was also unstable and disappeared after a few seconds, and the process ended with the appearance of a sink.

At the end of all experiments on the surface of the models, it was possible to observe a depression in a rather complex configuration, most often having clearly pronounced central and peripheral parts. The first one represents a sink; the second one is a subsidence surrounding it (Fig. 5). The sinks had a concave cup-like shape, sometimes complicated by subvertical shear deformations. The surface of the zones surrounding them was slightly inclined, slightly convex and, as a rule, had numerous cracks.

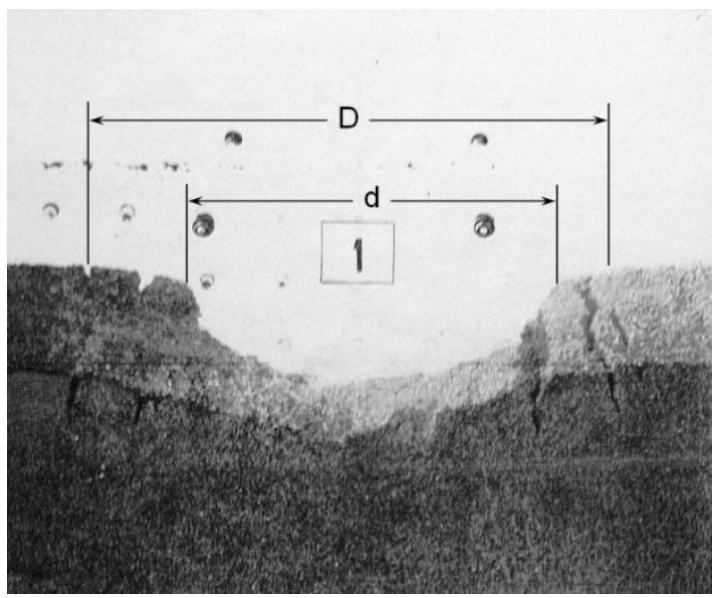

Fig. 5. Photograph of the model surface taken after the completion of experiment No.1 ( $d$ is the width of the sink; $D$ is the width of the depression).

Not all surface manifestations of the modeled processes were quite distinct. In six experiments it was impossible to determine the boundaries of the subsidence zone surrounding the sink, and in three - of the sink itself. However, it seems to be more important that the morphology of these forms fully corresponds to the morphology of large sinkholes recorded on the territory of Dzerzhinsk and its suburbs [13]. This clearly indicates a satisfactory adequacy of the models.

\section{Discussion}

\subsection{Solution of the prognostic task}

An analysis of the modelling results taking into account scale effects allowed proposing a conceptual model for the formation of sagging-collapse sinkholes, presented in the form of a graphic scheme (Fig. 6). According to this concept, the destruction of the clay layer that overlaps the karst cavity can be initiated by one of three factors: 1) expansion of the cavity as a result of dissolution of its walls; 2) output of water from soluble rocks; 3) input of 
water into the soil cover. The last two factors may be of man-made origin. A saggingsinkhole formation undergoes two stages in its development.

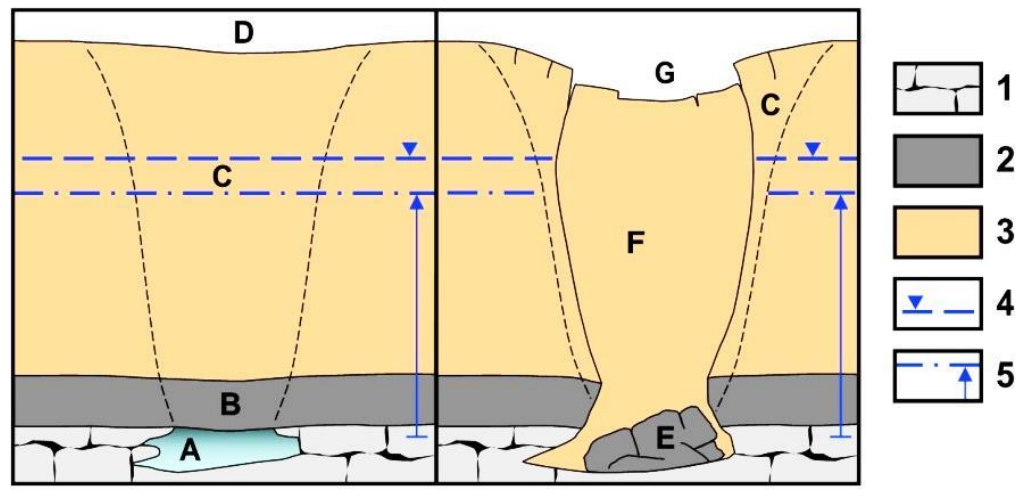

Fig. 6. First (left picture) and second (right picture) stages of a sagging-collapse sinkhole formation.

Where: 1, Soluble rocks. 2, Clays. 3, Sands. 4, Level of supra-karst unconfined groundwater. 5, Level of karst confined groundwater. A, Karst cavity filled with water under pressure. B, Zone of sagging and exfoliation of clays. C, Zone of smooth downward movement of sands. D, Subsidence. E, Collapsed clays. F, Zone of liquefaction and subsequent sharp downward movement of sands. G, Sinkhole.

At the first stage (left part of Fig. 6), when the initiating factor begins to act, the destruction of the water-resistant layer will take the form of its sagging into the cavity and exfoliation of the clays composing it. The sagging will be accompanied by a smooth downward movement of overlying sands, which, capturing large ground masses, can, under certain conditions, manifest itself on the earth's surface in the form of an increasing subsidence.

If the impact of the initiating factor continues, the destruction of soil cover will go into the second stage. It will come at that critical moment when the clays begin to fall into the karst cavity filled with water under pressure (right part of Fig. 6b). At the same time, three processes proceed almost simultaneously: the collapse of clays, the displacement of water from the cavity, and a sharp downward movement of sands. Their mutual superposition leads to the fact that pore pressure sharply rises in saturated sands above the cavity, as a result of which they pass to a liquefied state in a certain volume. This quicksand easily moves down, fills the karst cavity and ceases to serve as a support for unsaturated sands, which are also involved in a sharp downward movement that can reach the earth's surface forming a sink.

At the time of the collapse of the waterproof layer composing by clays, a dome appears on the free surface of the supra-karst groundwater, which disappears after the formation of the sinkhole. For this reason, cases of the appearance of water at the bottom of fresh sinkholes and its subsequent quick departure were repeatedly observed on the territory of Dzerzhinsk, which made it possible for Savarensky [14] to hypothesize the participation of sand liqufaction in the formation of sinkholes for the first time.

The results of the modelling in quantitative terms are presented in Table 2. The statistical processing of the obtained digital material was carried out sequentially in three areas in order to determine the critical width of the karst cavity $\left(2 a_{0}\right)$, the diameter of the sink $(d)$, and the diameter of the final depression $(D)$. As three dimensionless dependent variables, the ratios of these values to two parameters having a dimension of length were adopted: $M+m$ and $m$. The assignment to first dependent variable the dimensionless form 
$R=2 a /(M+m)$ required a change in the structure of the independent variables $Z_{2}$ and $Z_{3}$, which, respectively, took the form: $Z_{2}=M /(M+m)$ and $Z_{3}=H /(M+m)$.

Table 2. Digital data of the modelling.

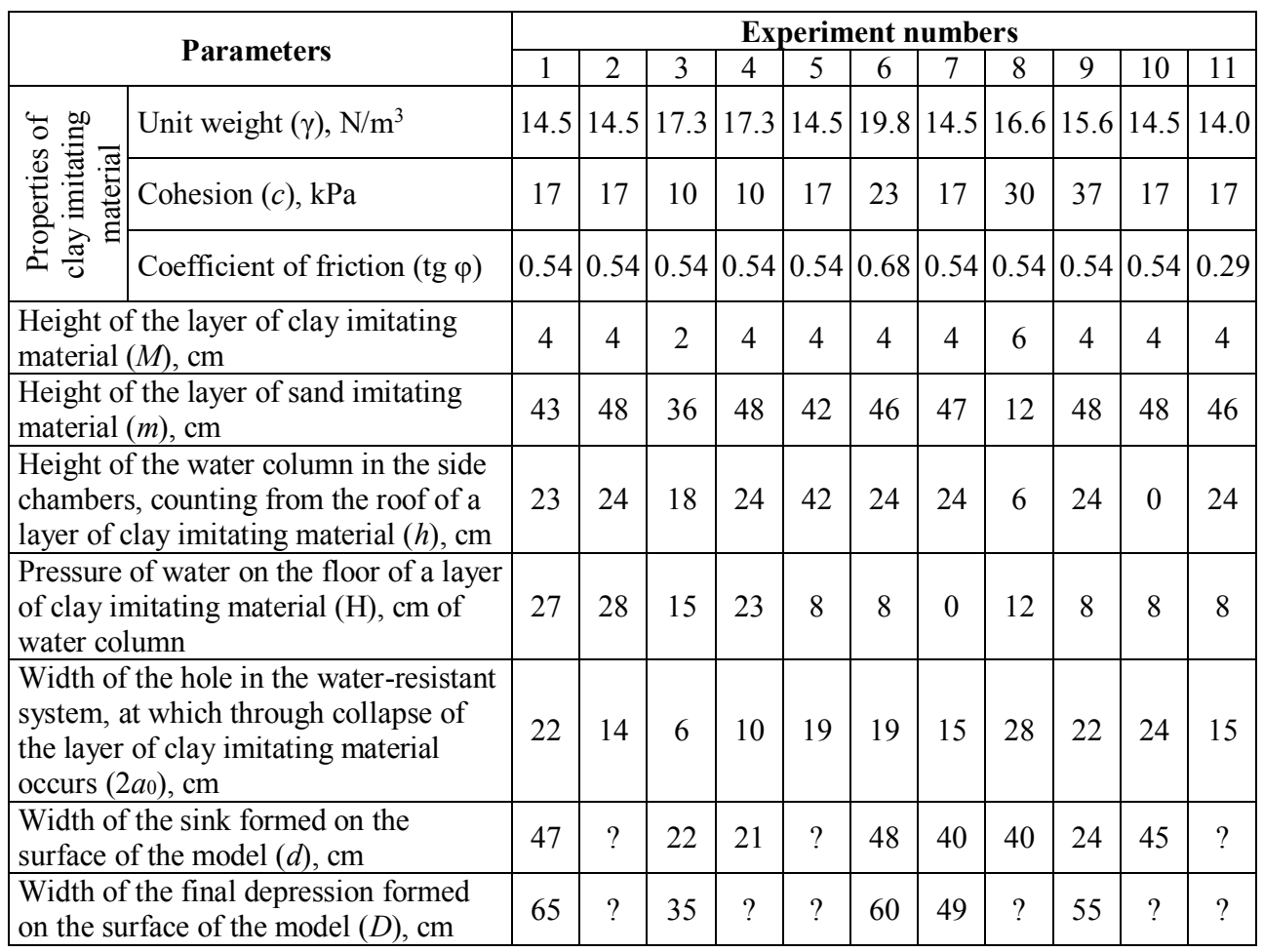

Note: "?" means that sink or final depression on the model's surface did not have clear boundaries.

To simplify both the statistical processing and the resulting mathematical expressions, the following type of pseudo-functions was selected that characterize the desired quantitative laws:

$$
F(R)=k_{0}+k_{1} f\left(Z_{1}\right) f\left(Z_{2}\right) \ldots f\left(Z_{n}\right)
$$

where $R$ is resulting dimensionless parameter, $Z$ is initial dimensionless parameter, $k$ is empirical coefficient, and $n$ is number of initial parameters.

The acceptability of such a structure of the final pseudo-function was evidenced by the high tightness of the obtained correlation dependencies. In all three cases, during statistical processing, it was possible to avoid the extremely undesirable inclusion of the dependent variable in any function.

Table 3 contains all dimensionless variables included in the statistical processing. The final predictive formulas were as follows:

$$
\begin{gathered}
2 a_{0}=0.115(M+m)+1.23 \operatorname{tg} \varphi \sqrt{c M / \gamma} \exp [H /(M+m)] \exp (-h / m) \\
d=1.48 \sqrt{2 a_{0} m} \exp (h / m)-0.566 m \\
D=(M+m)\left\{1.45-1.15 \operatorname{tg} \varphi \sqrt{\ln \left(m / 2 a_{0}\right)} \exp \left[-(d / m)^{2}\right]\right\}
\end{gathered}
$$

where $2 a_{0}$ is the critical width of the karst cavity, providing a through collapse of the clay layer (m), $M$ is its thickness (m), $m$ is thickness of the sands overlapping it $(\mathrm{m}), \varphi$ is 
friction angle of clays (degrees), $c$ is their cohesion $(\mathrm{kPa}), \gamma$ is their unit weight $\left(\mathrm{kN} / \mathrm{m}^{3}\right), H$ is hydraulic head of karst water $(\mathrm{m}), h$ is thickness of saturated sand $(\mathrm{m}), d$ is diameter of the sinkhole $(\mathrm{m})$, and $D$ is diameter of the weakened zone $(\mathrm{m})$.

Table 3. The results of statistical processing of experimental data.

\begin{tabular}{|c|c|c|c|c|c|c|}
\hline \multirow{2}{*}{$\begin{array}{c}\text { Experiment } \\
\text { numbers }\end{array}$} & \multicolumn{5}{|c|}{ Independent variables $(Z)$} & \multirow{2}{*}{$\begin{array}{c}\text { Dependent } \\
\text { variables }(R)\end{array}$} \\
\hline & $Z_{1}$ & $Z_{2}$ & $Z_{3}$ & $Z_{4}$ & $Z_{5}$ & \\
\hline \multicolumn{7}{|c|}{ 1. Determination of the critical width of karst cavity } \\
\hline 1 & 0.53 & 0.085 & 0.57 & 29 & 0.54 & 0.47 \\
\hline 2 & 0.50 & 0.077 & 0.54 & 29 & 0.54 & 0.27 \\
\hline 3 & 0.50 & 0.053 & 0.39 & 29 & 0.54 & 0.16 \\
\hline 4 & 0.50 & 0.077 & 0.44 & 14 & 0.54 & 0.19 \\
\hline 5 & 1.00 & 0.087 & 0.17 & 29 & 0.54 & 0.41 \\
\hline 6 & 0.52 & 0.080 & 0.16 & 29 & 0.68 & 0.38 \\
\hline 7 & 0.51 & 0.078 & 0 & 29 & 0.54 & 0.29 \\
\hline 8 & 0.50 & 0.333 & 0.67 & 30 & 0.54 & 1.56 \\
\hline 9 & 0.50 & 0.077 & 0.15 & 59 & 0.54 & 0.42 \\
\hline 10 & 0 & 0.077 & 0.15 & 29 & 0.54 & 0.46 \\
\hline 11 & 0.52 & 0.080 & 0.16 & 30 & 0.29 & 0.30 \\
\hline \multicolumn{7}{|c|}{$\begin{array}{c}\text { Approximation function: } Y=0.115+1.23 X \text {, where } X=Z_{2} Z_{5} \sqrt{Z_{4}} \exp Z_{3} \exp \left(-Z_{1}\right), Y=R \\
\text { Correlation coefficient: } 0.97\end{array}$} \\
\hline \multicolumn{7}{|c|}{$\begin{array}{c}\text { 2. Determination of the sinkhole's diameter } \\
Z_{1}=h / m ; Z_{2}=2 a_{0} / m ; R=d / m\end{array}$} \\
\hline 1 & 0.53 & 0.51 & - & - & - & 1.09 \\
\hline 3 & 0.50 & 0.17 & - & - & - & 0.61 \\
\hline 4 & 0.50 & 0.21 & - & - & - & 0.44 \\
\hline 6 & 0.52 & 0.41 & - & - & - & 1.04 \\
\hline 7 & 0.51 & 0.32 & - & - & - & 0.85 \\
\hline 8 & 0.50 & 2.33 & - & - & - & 3.33 \\
\hline 9 & 0.50 & 0.46 & - & - & - & 0.50 \\
\hline 10 & 0 & 0.50 & - & - & - & 0.94 \\
\hline \multicolumn{7}{|c|}{$\begin{array}{c}\text { Approximation function: } Y=-0.566+1.48 X \text {, where } X=\sqrt{Z_{2}} \exp Z_{1}, Y=R \\
\text { Correlation coefficient: } 0.95\end{array}$} \\
\hline \multicolumn{7}{|c|}{$\begin{array}{l}\text { 3. Determination of weakened zone's diameter } \\
Z_{1}=d / m ; Z_{2}=2 a_{0} / m ; Z_{3}=\operatorname{tg} \varphi ; R=D /(M+m)\end{array}$} \\
\hline 1 & 1.09 & 0.51 & 0.54 & - & - & 1.38 \\
\hline 3 & 0.61 & 0.17 & 0.54 & - & - & 0.92 \\
\hline 6 & 1.04 & 0.41 & 0.68 & $\begin{array}{llll}- & \\
\end{array}$ & - & 1.20 \\
\hline 7 & 0.85 & 0.32 & 0.54 & - & - & 0.96 \\
\hline 9 & 0.50 & 0.46 & 0.54 & - & - & 1.06 \\
\hline \multicolumn{7}{|c|}{ Approximation function: $\begin{aligned} Y= & 1.145-1.15 X, \text { where } X=Z_{3} \sqrt{-\ln Z_{2}} \exp \left(-Z_{1}^{2}\right), Y=R \\
& \text { Correlation coefficient: } 0.85\end{aligned}$} \\
\hline
\end{tabular}

An analysis of formula (3) shows that there must be boundary conditions that exclude the emergence of a sharp downward movement of sand to the surface. They are easy to find by introducing the zero value of $d$ into formula (3) and solving it as an equation. Conditions excluding collapse sink formation will then be expressed by the inequality:

$$
2 a_{0} \leq 0.146 m \exp (-2 h / m)
$$




\subsection{Verification of the forecast}

Nowadays, there are no methods and technical means to determine the size of karst cavities in the considered geological conditions. Nevertheless, knowledge of the critical width of the cavity at which the through collapse of the overlapping clay layer $\left(2 a_{0}\right)$ occurs is very important. The fact is that the critical width of the cavity characterizes the potential danger of sinkhole formation - the larger this value, the more intensively the process of dissolution of soluble rocks should occur so that it can lead to the sinkhole formation in a certain period of time. Therefore, parameter $2 a_{0}$ can act as an assessment criterion for the stability of the sinkhole-prone territory taking into account time, but only in combination with a certain indicator of the rate of the corrosion process. If we consider this parameter on the basis of the ideal assumption of a stable expansion rate of karst cavities, then its low values indicate a high potential danger of sinkhole formation.

Formula (2) indicates that the critical width of the karst cavity, which ensures the through collapse of the overlapping clay layer $\left(2 a_{0}\right)$, increases with an increase in its thickness $(M)$ and the depth of its floor $(M+m)$. This is fully consistent with the tendency for a decrease in the intensity of the sinkhole formation in places of increasing thickness of clay layer and immersion of the soluble rock's roof on the territory of Dzerzhinsk. Such a pattern was established by Tolmachev [15] during the mathematical processing of data on sinkholes using the apparatus of factor analysis.

It also follows from formula (2) that $2 a_{0}$ has a direct dependence on $H$ and an inverse on $h$, i.e. the critical width of the karst cavity decreases (and, accordingly, the danger of the formation of a sagging-collapse sinkhole increases) with a decrease in the pressure of karst water and when the level of supra-karst waters rises. In global practice, there are cases when sinkholes, apparently related to the genetic type under consideration, were triggered by a decrease in the pressure of karst waters [16] and by a rise in the level of supra-karst waters [17].

Good results were obtained by comparing prognostic decisions with information on the geological setting and the parameters of two sinkholes, which can be reliably attributed as sagging-collapse type. Both collapse sinks have been appeared in the industrial zone of Dzerzhinsk.

The first sinkhole appeared in September 1961 on the territory of a thermal power station and had a diameter of $26 \mathrm{~m}$. The diameter of the weakened zone was $42 \mathrm{~m}$. The drilling carried out near the sinkhole showed that the thickness of the sand layer is $24.3 \mathrm{~m}$, and of the clay layer $-9.9 \mathrm{~m}$. The level of supra-karst waters at that time was at a depth of $5.7 \mathrm{~m}$, and the piezometric head of karst waters was $28.7 \mathrm{~m}$. Inverse verification calculations using formulas (2), (3), and (4) indicate the fact that under these conditions for the formation of surface manifestations of such dimensions, it is necessary that the karst cavity has a width of $6.4 \mathrm{~m}$ at the time of collapse of clays. This result serves as an exhaustive explanation of the fact that the only borehole located inside the sinkhole at a distance of $4 \mathrm{~m}$ from its center, did not situated into the zone of the clay's collapse. According to the calculations, the cohesion of clays should be $27 \mathrm{~Pa}$, their friction angle should be $27^{\circ}$, and their unit weight $-20 \mathrm{kN} / \mathrm{m}^{3}$.

The second sinkhole with a diameter of $30 \mathrm{~m}$, surrounded by a weakened zone with a diameter of $50 \mathrm{~m}$, caused the damage to a factory building in July 1992 (Fig. 7). The borehole closest to the sinkhole, drilled almost immediately after its formation, allowed finding that soluble rocks are covered by clays with thickness $7.0 \mathrm{~m}$, over which there are sands of $40.0 \mathrm{~m}$ thick. According to measurements of groundwater levels carried out during drilling, the depth of the supra-karst waters was $14.0 \mathrm{~m}$ in the sinkhole area, and the piezometric head of the karst waters was $31.7 \mathrm{~m}$. Verification calculations gave the following results: $2 a_{0}=8.6 \mathrm{~m} ; c=84 \mathrm{kPa} ; \varphi=26^{\circ} ; \gamma=20 \mathrm{kN} / \mathrm{m}^{3}$. As in the first case, the calculated values of the strength properties of the clays fall into the real ranges established 
during site investigations in the industrial zone of the city. The cohesion of clays varies from $5 \mathrm{kPa}$ to $105 \mathrm{kPa}$, the angle of internal friction - from $30^{\circ}$ to $24^{\circ}$, respectively, and the unit weight - from $20 \mathrm{kN} / \mathrm{m}^{3}$ to $21 \mathrm{kN} / \mathrm{m}^{3}$.

It worth noting that, according to both verification's results, the calculated values of the critical width of the karst cavity, which ensures through collapse of the clay layer, are relatively small and are measured in first meters. Apparently, this is the reason for the wellknown difficulty of finding karst cavities that have not reached the critical size in the geological setting under consideration.

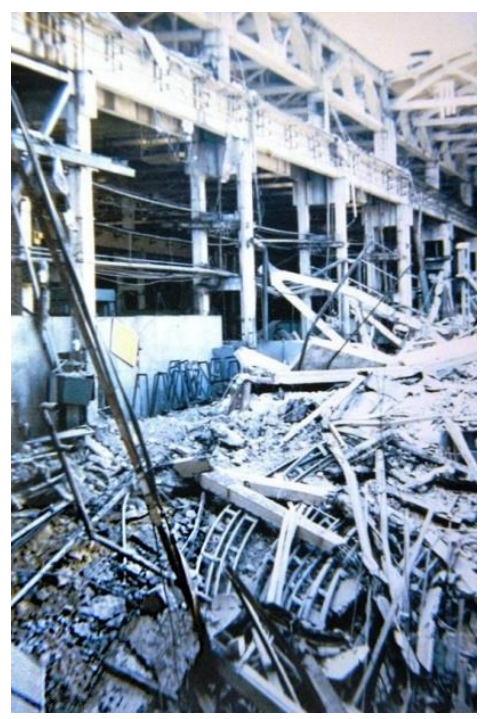

Fig. 7. The edge of the sagging-collapse sinkhole and the result of caused by its formation partially destruction of an industrial building (Dzerzhinsk, Nizhny Novgorod Region, 1992).

\section{Conclusions}

Sagging-collapse sinkholes have relatively complex mechanism of their formation owing to presence of saturated cohesionless soils above the clay layer covering soluble rocks. Inlaboratory simulation modelling of sagging-collapse sinkhole formation showed that it is caused by the destructive effect of not only gravitational but also hydrodynamic forces on the soil cover that overlaps the karst cavities.

Experiments were organized as a purposefully planned series. This made it possible not only to understand the mechanism of the process under study, but also to develop prognostic solutions, the reliability of which is confirmed by their comparison with the parameters of real sinkholes related to this genetic type. The modelling results also allowed explaining the nature of some phenomena and patterns identified in connection with the formation of karst sinkholes in the city of Dzerzhinsk, Nizhny Novgorod Region.

\section{Acknowledgements}

The author would like to acknowledge the assistance provided by many employees of the enterprise "Antikarst and River Bank Protection" (Dzerzhinsk, Nizhny Novgorod Region), where the modelling has been carried out. He gratefully thanks G.F. Gladtsinov for technical service of the experimental equipment, S.E. Pidyashenko for performance of experiments according to the author's design, R.B. Davyd'ko and T.V. Mamonova for the 
preparation of model materials. Special thanks to Andrei Bars, who died tragically, not having time to complete the processing of data obtained by his device (RVINDS-P-03 radio wave indicator) during the modelling. However, full technical support for all experiments was provided by him.

\section{References}

1. M.A. Soriano, Encyclopedia of Natural Hazards. Encyclopedia of Earth Sciences Series (Sinkhole, 2013)

2. B.F. Beck, Proc. 1st multidiscipl. conf. on sinkholes. IX-X (1984)

3. A.C. Waltham, P.G. Fookes, J. Eng. Geol. Hydrogeol. 36, 101-118 (2003)

4. F. Gutiérrez, A.H. Cooper, K.S. Johnson, Environ. Geol. 53(7), 1008-1022 (2008)

5. E.D. Zisman, Proc. 11th multidiscipl. conf. Geotechnical special publication 183, 278287 (2008)

6. V.P. Khomenko, V.V. Tolmachev, Encyclopedia of Engineering Geology. Encyclopedia of Earth Sciences Series (Sinkholes, 2018)

7. T. Waltham, F.G. Bell, M.G. Culshaw, Sinkholes and subsidence: karst and cavernous rocks in engineering and construction (Springer/Praxis Publishing, Chichester, 2005)

8. M.J. Byle, Proc. 15th multidiscipl. Conf. on Sinkholes and the Eng. and Environ. Impacts of karst and 3rd Appalachian karst symp. NCKRI Symp. 7, 47-52 (2018)

9. V.P. Khomenko, M.V. Leonenko, Geotechnical Engineering for Infrastructure and Development. Proc. XVI ECSMGE. Edinburgh, UK, Slopes and geohazards 4, 22692274 (2015)

10. V.P. Khomenko, E.P. Makhan'ko, E.I. Isaev, RF Patent No. 1823923 A3, class. G $01 \mathrm{~N}$ 15/08, Bulletin No. 23 (1993)

11. D.C. Montgomery, Design and Analysis of Experiments. 8th Edition (John Wiley \& Sons Inc., Hoboken New Jersey, 2013)

12. V.S. Istomina, V.V. Burenkova, G.V. Mishurova, Filtration strength of clay soils (Stroyizdat, Moscow, 1975)

13. A.N. Ilyin, A.P. Kapustin, I.A. Kogan, Gorky region. Proc. of LGGP named after Savarensky (Publishing House of the Academy of Sciences of the USSR, Moscow, 1960)

14. A.P. Savarensky, Abstract of the report to a meeting on summarizing the experience of scientific research, survey, design, construction and operation of structures in the areas of karst propagation, 125-126 (1965)

15. V.V. Tolmachev, G.M. Troitsky, V.P. Khomenko, Engineering and construction development of karstified territories (Stroyizdat, Moscow, 1986)

16. I.I. Plotnikov, S.G. Dubeykovsky, Int. Geol. Congr., 25th session. Reports of Soviet geologists. Geology of the Quaternary, 217-224 (1976)

17. Z. Wilk, J. Motyka, J. Niewdana, Bulletin of Geological Institute 3(277), 359-373 (1973) 